ISSN: 1980-055X

NOTA DE PESQUISA

\title{
COMPARAÇÃO ENTRE A NORMAL CLIMATOLÓGICA DE 1961-1990 E O PERÍODO 1991-2007 PARA A PRECIPITAÇÃO NA CIDADE DE MANAUS-AM
}

\author{
Tongaté Arnaud Mascarenhas Junior ${ }^{39}$ \\ Jaci Maria Bilhalva Saraiva ${ }^{40}$ \\ Francisco Evandro Oliveira Aguiar ${ }^{41}$
}

\begin{abstract}
RESUMO
Este trabalho tem como objetivo fazer a comparação entre a Normal Climatológica 1961-1990 e o período de dados subseqüente, de 1991-2007, que corresponde a 17 anos de dados, a fim de verificar possíveis modificações nos valores médios, tendo como base o parâmetro precipitação para a cidade de Manaus, localizada na Amazônia Central. O período 1991-2007 foi analisado de duas formas: foi subdividido em dois (1991-2000 e 2001-2007) para uma análise setorial dos períodos e posteriormente reunificado para as considerações finais. Foram utilizados os dados das planilhas diárias fornecidas pelo Instituto Nacional de Meteorologia - INMET. No período 1991-2007 foram também identificados episódios de precipitação acima de $30 \mathrm{~mm}$ diários, separados em duas faixas de análise para fins metodológicos: entre 30 e $49 \mathrm{~mm}$, convencionados medianos para este trabalho; e acima de $50 \mathrm{~mm}$, que podem ser considerados severos de acordo com alguns fatores, como a duração do episódio e o impacto que este causou no ambiente atingido. Eventos de grande escala como El Niño e La Niña foram identificados neste último período e tiveram certa influência em alguns anos. Os resultados apresentados nesse trabalho mostram que $47,2 \%$ dos dias do período foram chuvosos e destes, $12,65 \%$ apresentaram precipitação igual ou superior a $30 \mathrm{~mm}$ diários. Também foram verificadas modificações dos meses mais chuvoso e mais seco na comparação entre a Normal Climatológica 1961-1990 e o período 1991-2007 e diminuição dos dias de chuva totais na verificação ano a ano. No período 19912007 nenhum ano apresentou mais de 200 dias de chuvas, o que aconteceu por várias vezes no período da Normal. Porém, neste caso específico, não se pode descartar a possibilidade de falhas nos dados.
\end{abstract}

Palavras-chave: Normal Climatológica; Precipitação; Eventos Extremos; Manaus.

39 Licenc. em Geografia, Mestrando do Prog. de Pós-Graduação em Geografia, UFAM, Manaus-AM. Email: tamjunior@ig.com.br

40 Professora Doutora em Meteorologia, SIPAM - Sistema de Proteção da Amazônia.

${ }^{41}$ Professor Doutor em Geografia, Ufam - Universidade Federal do Amazonas. 


\section{ABSTRACT}

This work had as objective to do the comparison among the Climatological Normal 1961-1990 and the period of data subsequent, of 1991-2007, that corresponds to 17 years of data, in order to verify possible modifications in the medium values, presenting as base the parameter rainfall for the city of Manaus, located in the Amazonian Central. The period 1991-2007 was analyzed in two ways: it was subdivided in two (1991-2000 and 2001-2007) for a sectorial analysis of the periods and later reunified for the final considerations. Were used the data of the daily spreadsheets supplied by the National Institute of Meteorology - INMET. In the period 1991-2007 were also identified rainfall episodes above $30 \mathrm{~mm} /$ day, separate in two analysis strips for methodological ends: between 30 and $49 \mathrm{~mm}$, stipulated medium for this work; and above 50 $\mathrm{mm}$, that can be considered severe in agreement with some factors, as the duration of the episode and the impact that this caused in the reached atmosphere. Events of large scale as El Niño and La Niña were identified in this last period and they had certain influence in some years. The results presented in that work show that $47,2 \%$ of the days of the period were rainy and of these, $12,65 \%$ presented rainfall same or superior to $30 \mathrm{~mm} /$ day. Modifications of the rainiest and drier months were also verified in the comparison among the Climatological Normal 1961-1990 and the period 1991-2007 and decrease of the days of rain total in the verification year to year. In the period 1991-2007 no year presented more than 200 days of rains, what happened for several times in the period of the Normal. However, in this specific case, it cannot discard the possibility of flaws in the data.

Key-words: Climatological Normal; Rainfall; Extreme climatic events; Manaus.

\section{INTRODUÇÃO}

A precipitação na Região Amazônica é causada por vários processos de grande e meso escalas. Como eventos de grande escala podem-se destacar a Zona de Convergência Intertropical (ZCIT), as Células de Walker e Hadley e a Alta da Bolívia (MOLION,1987). Em termos de meso-escala pode-se destacar as linhas de instabilidade, responsáveis por quase metade da chuva que cai na região nos meses mais secos (COHEN, 1989). Estes eventos, juntamente com a disponibilidade de energia solar são os responsáveis pelo clima na região. Segundo a O.M.M a Normal Climatológica é a média de uma série de dados climáticos de trinta anos. No século XX foram convencionadas três Normais: de 1901 a 1930, de 1931 a 1960 e de 1961 a 1990.

Este trabalho teve como objetivo, usando o parâmetro precipitação, fazer a comparação entre a última Normal Climatológica do século XX, entre 1961 e 1990 e o período de dados subseqüente, de 1991 a 2007, para a cidade de Manaus verificando diferenças e semelhanças nos valores de precipitação encontrados, observando as ocorrências de eventos El Niño e La Niña nos períodos. Também procurou identificar, no período 1991-2007, os episódios de precipitação, trabalhando duas faixas: valores entre $30-49 \mathrm{~mm}$ (medianos) e acima de $50 \mathrm{~mm}$ diários (severos), que podem ser ditos extremos, considerando a realidade amazônica, bastante diferente em comparação com as outras 
regiões brasileiras e os impactos causados por estes eventos no perímetro urbano. Segundo ESPÍRITO SANTO (2002), eventos de $40 \mathrm{~mm}$, se ocorrerem em curto espaço de tempo, podem causar muitos danos em grandes metrópoles, como São Paulo. Porém, em uma área de floresta, um evento desta magnitude não causa grandes impactos.

\section{MATERIAL E MÉTODOS}

Para este trabalho foram usados dados diários de precipitação do Instituto Nacional de Meteorologia - INMET para Manaus. Os valores da Normal Climatológica 1961-1990 foram comparados ao período subseqüente, de 1991 a 2007. Neste período, com dados diários de precipitação, procurou-se observar episódios de precipitação acima de $30 \mathrm{~mm}$ diários, separando-os em duas faixas para uma melhor observação dos dados: de 30 a $49 \mathrm{~mm}$, que convencionou-se chamar medianos para este trabalho; e acima de $50 \mathrm{~mm}$ que podem ser considerados severos de acordo com alguns fatores como a duração do episódio ou o impacto causado no ambiente. Estes valores foram escolhidos devido à localização da cidade de Manaus, em meio a maior floresta tropical do mundo, a Floresta Amazônica, o que certamente Ihe dá características diferenciadas em relação a outras metrópoles brasileiras.

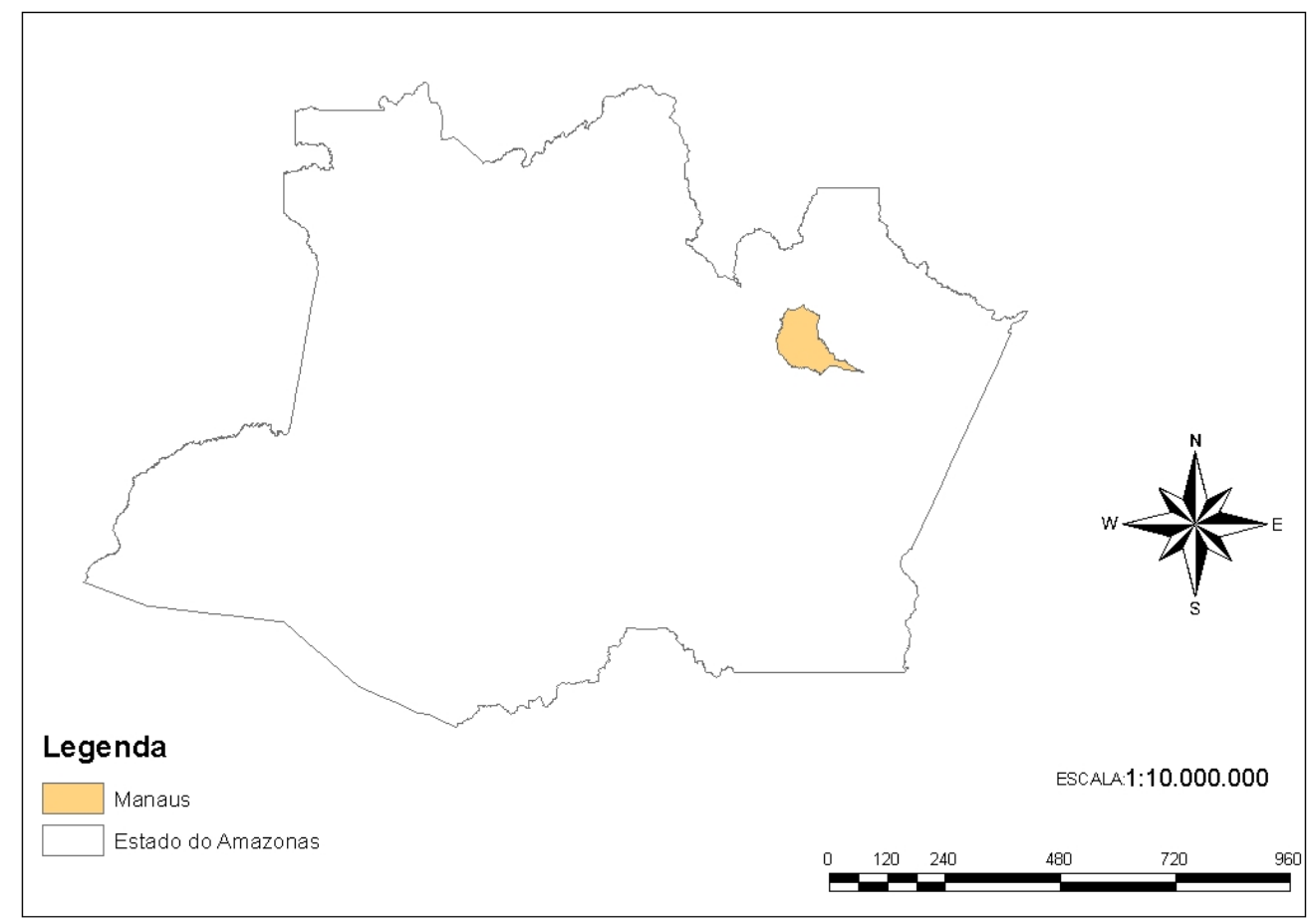

Figura 1 - Localização de Manaus (AM)

Procurou-se relacionar sempre que possível os dados coletados aos eventos El Nino e La Nina ocorridos nos períodos, que tiveram alguma influência na precipitação. O período 1991-2007 foi ainda subdividido em dois (19912000 e 2001-2007) para uma análise setorial por meio de gráficos produzidos no software Excel, a fim de verificar possíveis tendências, sempre em 
comparação com a Normal 1961-1990, e nas últimas análises foi reunificado para as considerações finais.

\section{RESULTADOS E DISCUSSÃO}

\section{1 - A normal climatológica 1961 a 1990:}

Segundo FISCH, MARENGO \& NOBRE (1996), a média de precipitação na Amazônia é de $2300 \mathrm{~mm}$ anuais. No extremo oeste da região, próximo à cordilheira dos Andes, a média fica em torno de $3500 \mathrm{~mm}$ anuais sem período de seca definido, basicamente devido à ascensão orográfica da umidade. No extremo leste-nordeste amazônico, também são verificadas altas médias de precipitação, porém isso se deve as linhas de instabilidade q se formam naquela região, entre o Amapá e o Pará.

A precipitação na região central da Amazônia possui dois períodos bem definidos. A cheia, que vai de dezembro a maio, com precipitação mensal acima de $200 \mathrm{~mm}$ e a seca, com precipitação menor que $200 \mathrm{~mm}$ mensais, que é verificada entre os meses de junho a novembro. Historicamente, observando-se os valores da Normal Climatológica 1961-1990, o mês mais chuvoso é março e o menos chuvoso é agosto.

Quadro 1 - Valores da Normal Climatológica 1961-1990 para precipitação em Manaus.

\begin{tabular}{|l|r|l|r|}
\hline Meses & $\begin{array}{c}\text { Normal } \\
\text { Climatológica } \\
\text { 1961-1990 }\end{array}$ & Meses & $\begin{array}{c}\text { Normal } \\
\text { Climatológica } \\
\mathbf{1 9 6 1 - 1 9 9 0}\end{array}$ \\
\hline janeiro & 260 & julho & 90 \\
\hline fevereiro & 290 & agosto & 60 \\
\hline março & 310 & setembro & 80 \\
\hline abril & 300 & outubro & 130 \\
\hline maio & 260 & novembro & 180 \\
\hline junho & 110 & dezembro & 220 \\
\hline
\end{tabular}

Fonte: Inmet. Adaptação de Tongaté A. M. Junior

No quadro 1, são mostrados os valores de precipitação da Normal Climatológica 1961-1990 para a cidade de Manaus. É possível observar claramente os períodos de chuva e seca citados anteriormente.

Medidas feitas em Manaus indicam que é no período seco que os maiores totais de radiação que chegam na superfície ocorrendo nos meses de setembro e outubro, sendo que os mínimos são nos meses de Dezembro, janeiro e Fevereiro (FISCH, MARENGO \& NOBRE, 1996).

Durante o período da Normal houve ocorrência de nove eventos El Niño (3 na década de 60, 4 na década de 70 e 2 na década de 80 ) e seis eventos La Niña ( 1 na década de 60, 3 na década de 70 e 2 na década de 80). Estes eventos atuam na Amazônia pelo deslocamento provocado pela célula de Walker, o que modifica temporariamente os padrões existentes. Em períodos de El Nino a tendência é de redução de chuvas, enquanto com a atuação do La Nina, a tendência é de aumento da precipitação. Provavelmente estes eventos 
atuaram de forma decisiva na alteração dos padrões pluviométricos no período, porém, apenas com os valores da Normal, não é possível fazer essa afirmação com certeza. No quadro 2 foram separados os eventos El Nino e La Nina ocorridos no período da Normal Climatológica 61-90.

Quadro 2 - Anos de ocorrência de El Niño e La Nina durante a Normal 19611990

\begin{tabular}{|l|l|}
\hline Eventos de El Niño & Eventos de La Niña \\
\hline jun/63 a fev/64 & mai/64 a jan/65 \\
\hline mai/65 a jun/66 & jul/70 a jan/72 \\
\hline set/68 a mar/70 & jun/73 a jun/74 \\
\hline abr/72 a mar/73 & set/74 a abr/76 \\
\hline ago/76 a mar/77 & set/84 a jun/85 \\
\hline jul/77 a jan/78 & mai/88 a jun/89 \\
\hline out/79 a abr/80 & \\
\hline abr/82 a jul/83 & \\
\hline ago/86 a fev/88 & \\
\hline
\end{tabular}

Fonte: Sousa, Edna Pinto Pereira. Adaptação de Tongaté A. M. Junior

Os eventos El Niño coincidem com alguns dos anos menos chuvosos da série, como 1963, 1972 e 1987, todos com precipitação abaixo dos 2000 mm anuais. O El Niño considerado mais forte entre todos no período, que ocorreu entre abril/82 e jul/83, (SOUSA, 2004) não parece ter influenciado decisivamente na redução da precipitação no período.

Os eventos La Niña de jul/70 a jan/72 e de maio/88 a jun/89 (este o mais significativo do período, SOUSA, 2004) coincidem com os dois anos mais chuvosos do período da Normal. Em 1971, a precipitação acumulada foi de $3009,1 \mathrm{~mm}$ e em 1989 foi de 3113,4 mm.

Observando os dados anteriores pode-se afirmar que apenas alguns dos eventos El Nino e La Nina que ocorreram no período tiveram influência na alteração da precipitação para a cidade de Manaus. Não podem ser desprezados outros fatores como a formação das linhas de instabilidade e a expansão urbana da cidade, que cresce desordenadamente desde a década de 1960.

\section{2 - A série de dados 1991-2007}

A série de 1991 a 2007 corresponde a 17 anos de dados. Seria possível elaborar a Normal Provisória para a década de 1990, porém não seria possível realizar o mesmo procedimento para o restante do período, de 2001 a 2007, porque segundo a Organização Meteorológica Mundial, uma Normal Provisória representa as condições médias dos últimos 10 anos (KRUSCHE \& SARAIVA, 2001).

Voltando a atenção para a quantidade de eventos de precipitação dentro das faixas estabelecidas, apesar de não ser possível fazer uma relação direta entre precipitação anual e dias de chuva por ano, pode-se observar que o ano mais chuvoso também teve maior quantidade de eventos severos (acima de $50 \mathrm{~mm}$ ), 15 no total. O ano de 2001 foi o menos chuvoso, porém teve 30 dias de 
chuva a mais que o ano com menor quantidade de dias chuvosos no período, que foi 1997, com 143 dias com chuvas. Este ano, inclusive é um exemplo que mostra a concentração da precipitação. Mesmo não sendo o ano com menos dias de chuva, o ano de 2001 foi o que concentrou a menor ocorrência de eventos entre $30-49 \mathrm{~mm}$ e acima de $50 \mathrm{~mm}$ diários (4 e 5 respectivamente)

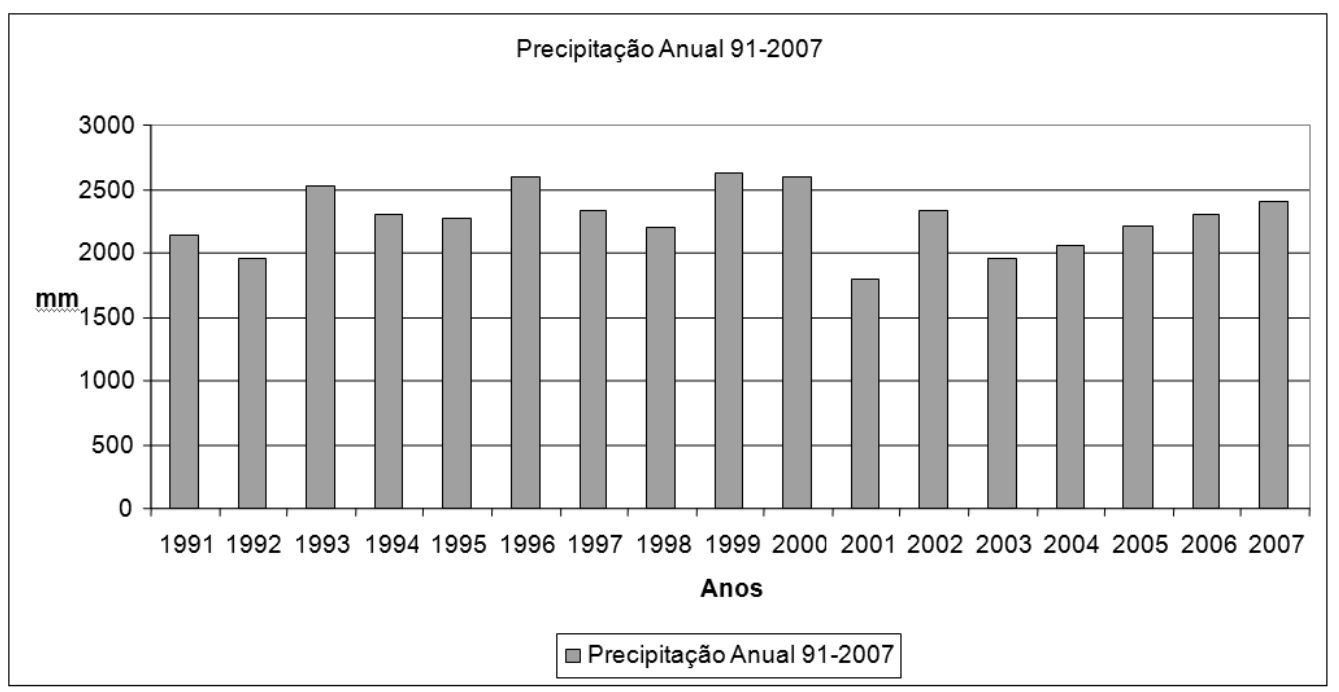

Gráfico 1 - Precipitação Anual no Período 1991-2007

Este período não pode ser considerado uma "meia normal", mas contribui para se entender o comportamento climático na última década do século XX e início dos anos 2000. Por isso, para efeito de análise, o período foi repartido em dois, 91-2000 e 2001-2007.Também foi observado, para o período em questão, a quantidade diária de precipitação, elaborando-se duas faixas: entre 30-49 $\mathrm{mm}$, considerados medianos e acima de $50 \mathrm{~mm}$, considerados severos. Estas faixas foram elaboradas para facilitar a análise dos eventos, que mostram certa freqüência de ocorrência na primeira faixa proposta e uma ocorrência menor na segunda faixa, de forma geral (quadro 3 ).

No Gráfico 1 estão colocados os totais anuais de chuva no período estudado. Os anos de 1996, 1999 e 2000 foram os de maior precipitação com 2595,2, 2620,3 e 2599,6 mm precipitados respectivamente e estavam sob efeito do evento La Nina, enquanto o ano 2001 foi o de menor precipitação, com apenas $1798,4 \mathrm{~mm}$ de chuva, bem abaixo da média amazônica. Entretanto não se pode relacionar este fato ao El Nino.

Na década de 1990 ocorreram 4 eventos El Nino e 2 eventos La Nina. O ano de 1992, o mais seco da década 1950, com $2 \mathrm{~mm}$ precipitados, estava sob influência do El Niño. Já o período compreendido entre 2001 e 2007, teve 2 episódios El Niño em 2002/2003 e 2006/2007 e um La Niña, que começou em 2007 e está em curso.

\section{3 - Eventos de precipitação na série 1991-2007}

Pode-se destacar no período estudado grande quantidade de eventos de precipitação considerados extremos. A realidade amazônica, bastante diferente de outras regiões do Brasil, permite trabalhar com parâmetros diferenciados 170 
com relação à questão dos extremos de precipitação. Além dos fenômenos de grande e meso escalas que trazem chuva para região, também é importante frisar que a floresta, através da evapotranspiração é grande fornecedora de umidade e, portanto, também contribui para a quantidade de chuva que cai na região.

No quadro 3 estão dispostos a precipitação anual no período, os dias de chuva e os eventos entre 30-49 (medianos) e acima de $50 \mathrm{~mm}$ diários (severos). Dos 6209 dias do período, 2932 dias foram chuvosos $(47,2 \%)$ e entre os dias chuvosos, 371 apresentaram precipitação igual ou superior a $30 \mathrm{~mm}$ diários $(12,65 \%)$. Pode-se perceber que os anos com maior quantidade de dias chuvosos não são os anos efetivamente mais chuvosos. Por exemplo, o ano mais chuvoso do período, 1999, não é o ano com maior quantidade de dias chuvosos. O mesmo se aplica ao ano menos chuvoso do período, 2001, que também não é o ano com menos dias de chuva. Isso indica, de forma geral, uma maior concentração da precipitação, e conseqüentemente, a um aumento da precipitação média diária.

Os três últimos anos do período, 2005, 2006 e 2007 foram os que apresentaram maior quantidade de eventos medianos e o ano de 2006, mesmo não sendo o mais chuvoso, nem o com maior número de dias com chuva, foi o que concentrou a maior quantidade de episódios de precipitação considerados medianos, entre 30-49 $\mathrm{mm}$.

Também é importante destacar que nenhum dos anos do período teve mais de 200 dias de chuva no período, fato que ocorreu em diversos anos do período da Normal 1961-2007.

Quadro 3 - Precipitação anual, dias de chuva e eventos entre $30-49 \mathrm{~mm}$ e acima de $50 \mathrm{~mm}$ diários de precipitação.

\begin{tabular}{|c|c|c|c|c|}
\hline anos & Precipitação Anual & Dias de Chuva & $\mathbf{3 0 - 4 9} \mathbf{~ m m}$ & acima de 50mm \\
\hline $\mathbf{1 9 9 1}$ & 2138 & 171 & 14 & 7 \\
\hline $\mathbf{1 9 9 2}$ & 1950,2 & 163 & 12 & 6 \\
\hline $\mathbf{1 9 9 3}$ & 2523,4 & 190 & 15 & 11 \\
\hline $\mathbf{1 9 9 4}$ & 2302,1 & 191 & 13 & 7 \\
\hline $\mathbf{1 9 9 5}$ & 2261,4 & 164 & 15 & 8 \\
\hline $\mathbf{1 9 9 6}$ & 2595,2 & 167 & 14 & 10 \\
\hline $\mathbf{1 9 9 7}$ & 2329,2 & $\mathbf{1 4 3}$ & 16 & 9 \\
\hline $\mathbf{1 9 9 8}$ & 2200,4 & 172 & 11 & 7 \\
\hline $\mathbf{1 9 9 9}$ & 2620,3 & 177 & 11 & $\mathbf{1 5}$ \\
\hline $\mathbf{2 0 0 0}$ & 2599,6 & 192 & 10 & 10 \\
\hline $\mathbf{2 0 0 1}$ & 1798,4 & 173 & $\mathbf{4}$ & 5 \\
\hline $\mathbf{2 0 0 2}$ & 2322,1 & 177 & 16 & 6 \\
\hline $\mathbf{2 0 0 3}$ & 1954,9 & 160 & 9 & 7 \\
\hline $\mathbf{2 0 0 4}$ & 2056,9 & 171 & 15 & 6 \\
\hline $\mathbf{2 0 0 5}$ & 2208,1 & 163 & 19 & 7 \\
\hline $\mathbf{2 0 0 6}$ & 2304,7 & 169 & 20 & 10 \\
\hline $\mathbf{2 0 0 7}$ & 2404,4 & 189 & 17 & 9 \\
\hline
\end{tabular}

\section{4 - Comparação entre normal 1961-1990 e a série 1991-2007}

Para elaborar a comparação entre os valores de precipitação da Normal Climatológica 1961-1990 e o período 1991-2007, o período de 17 anos foi 
subdividido em dois: 1991-2000 e 2001-2007. No gráfico 2, observa-se a comparação entre a Normal e o primeiro sub-período.

Historicamente o mês de março é o mais chuvoso, tendência que não se confirma na comparação com o sub-período 91-2000. O mês de abril é o mais chuvoso do período com média de $377,4 \mathrm{~mm}$ precipitados, seguido pelo mês de janeiro, com 346,4 mm. Março aparece como o terceiro mês mais chuvoso nesta série.

Para o mês mais seco também houve modificação entre a Normal e o sub-período 91-2000. O mês mais seco deixou de ser agosto. Julho foi mais seco, com média de apenas $58,3 \mathrm{~mm}$ precipitados.

O único mês do período chuvoso em que a Normal manteve valores acima dos do período foi maio. No período seco, entre junho e novembro, a Normal manteve valores acima dos do período, exceto nos meses de agosto e setembro. Isso indica que para o sub-período 91-2000, as estações secas foram um pouco mais severas.

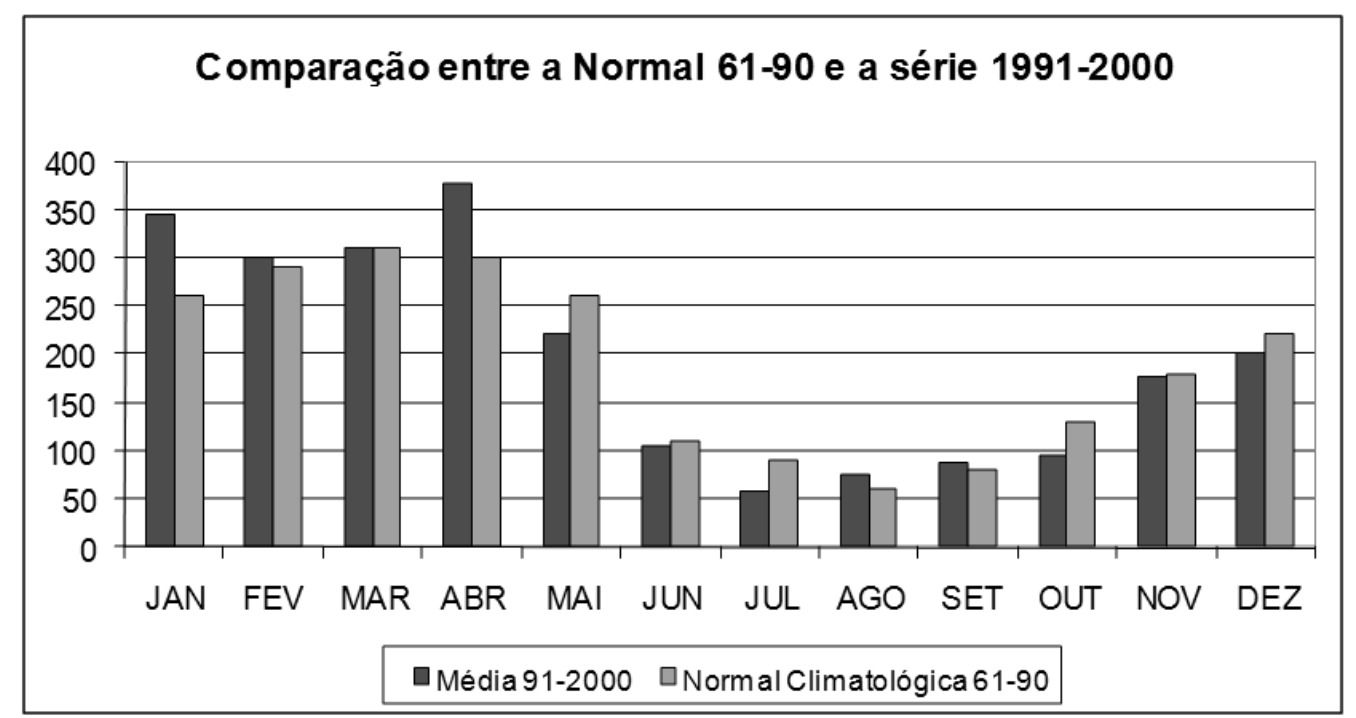

Gráfico 2: Comparação entre os valores da Normal 61-90 e o sub período 1991-2000 - Médias de precipitação para Manaus

Para o sub-período 2001-2007, mostrado em comparação com o subperíodo anterior, apenas os meses de maio, junho, julho e dezembro apresentam médias de precipitação superiores, como pode-se observar no gráfico 3, que apresenta a comparação entre o sub-período 2001-2007 e a Normal 61-90. O mês de abril continuou sendo o mais chuvoso, porém também com média inferior à do período anterior.

Em comparação com a Normal 61-90, o sub-período 2001-2007 teve cinco meses com médias superiores as da Normal: abril, maio, junho, agosto e dezembro, sendo o primeiro e o último da estação chuvosa e os restantes da estação seca. E manteve também o mês de julho como o mais seco, diferentemente da Normal. 


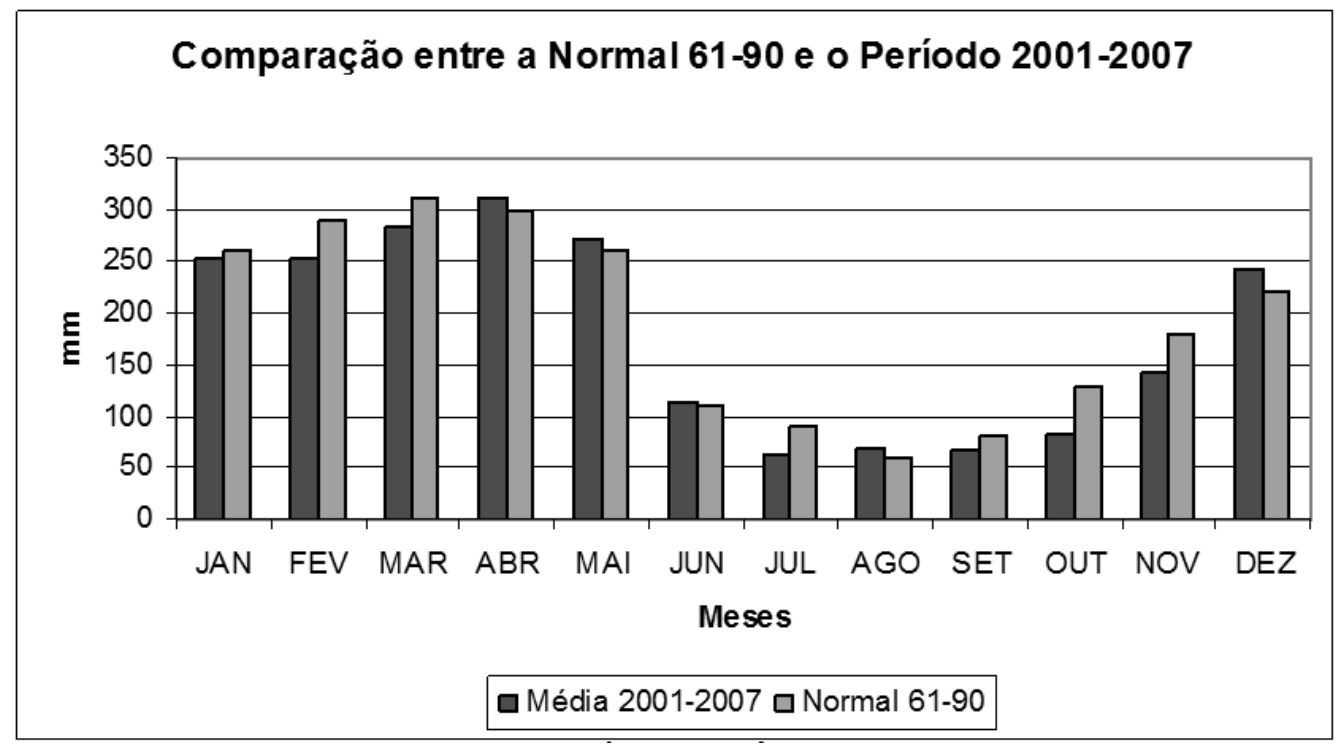

Gráfico 3 - Comparação entre os valores da Normal 61-90 e o Período 20012007 - Médias de precipitação para Manaus

O gráfico 4 traz a comparação entre o período 1991-2007 e a Norma Climatológica 1961-1990. Reagrupando os dois sub-períodos (1991-2000 e 2001-2007) em um novamente (1991-2007), pode-se fazer a comparação direta com a Normal 1961-1990.

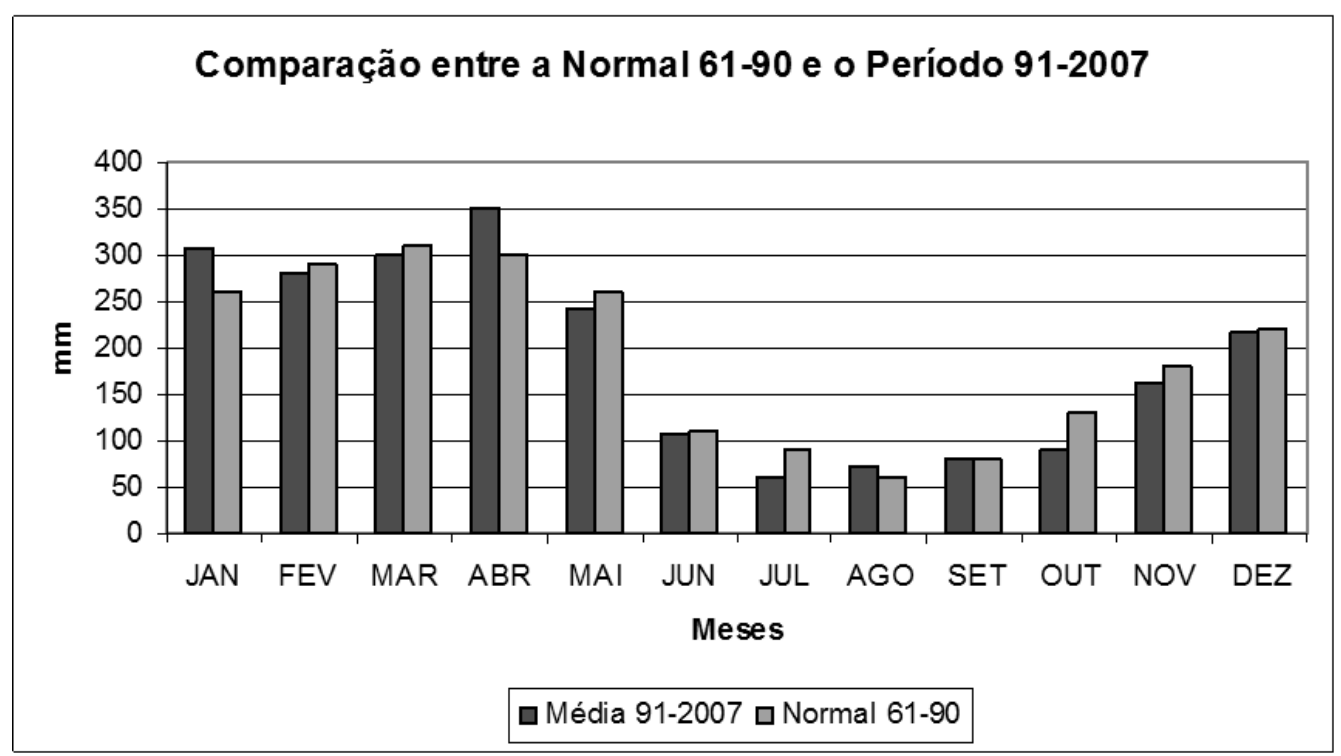

Gráfico 4 - Comparação entre os valores da Normal 61-90 e o Período 19912007 - dias de precipitação para Manaus

Observa-se no gráfico 4 que vários parâmetros mostram tendência de mudança. O mês mais chuvoso é abril e o menos chuvoso agora é julho, diferentemente da Normal, em que os meses extremos são março e agosto. Outro aspecto interessante é que no período chuvoso apenas os meses de janeiro e abril tiveram valores maiores no período 91-2007 do que na Normal, 
apesar de os valores dos outros meses (dezembro, fevereiro, março e maio) ficarem bem próximos. No período seco, apenas o mês de agosto teve média de precipitação superior ao da Normal e nos meses de julho e outubro essas médias foram bem inferiores.

\section{CONCLUSÕES}

A comparação entre os valores de precipitação da Normal Climatológica 1961-1990 e o período de dados 1991-2007 para a cidade de Manaus, situada na Amazônia Central, mostra um quadro diferenciado entre os períodos. Apesar de não se poder afirmar com certeza plena, pois ainda faltam 13 anos para que a Normal 1991-2020 se complete, é possível verificar certas tendências na análise dos dados apresentado neste trabalho.

Por exemplo, através dos dados pode-se afirmar que a média de precipitação aumentou para o período chuvoso e diminuiu para o período seco da Normal para o período proposto. Isto significa dizer que na estação chuvosa em média, choveu mais e na estação seca choveu menos no período 19912007.

Este fato pode estar sendo causado por vários fatores: Em grande escala, os eventos El Niño e La Niña que vem ocorrendo no período; em meso escala, as linhas de instabilidades formadas no nordeste do Pará e que entram pela região; e em micro escala as condições locais da cidade de Manaus e seu entorno com o aumento das áreas impermeabilizadas, da emissão de gases causadores do efeito estufa, provenientes dos automóveis e das fábricas e outros fatores que provocam localmente a ilha de calor. Essa retenção de calor pode explicar em parte o aumento da precipitação juntamente com a redução de dias precipitados no período de dados proposto, o que tende a gerar mais dias com precipitação mais intensa. Contudo, neste caso específico, não se pode descartar a possibilidade de falha nos dados de precipitação.

Com este trabalho espera-se ainda que timidamente, e mesmo não se configurando como o objetivo principal, começar uma discussão sobre o que pode ser considerado evento extremo de precipitação na região amazônica, pois entende-se que nessa região quaisquer dos parâmetros adotados para o restante do pais têm que ser revistos para que se possa mostrar a realidade de forma mais objetiva.

\section{REFERÊNCIAS}

COHEN, J. C. P. Um Estudo observacional de linhas de instabilidade na Amazônia. 1989. 153 f. Dissertação (Mestrado) - Instituto de Pesquisas Espaciais, São José dos Campos, SP.

ESPIRITO SANTO, C. M. do \& PRAKKI, S. Eventos extremos de precipitação na região sudeste do Brasil e redondezas no período de 1997-2001. XII Congresso Brasileiro de Meteorologia, p. 397-402. Foz do Iguaçu, 2002.

FISCH, G; MARENGO, J. A. \& NOBRE, C. A. Clima da Amazônia. Revista Climanálise, 1996. 
KRUSCHE, N. \& SARAIVA, J. M. B. Normais climáticas provisórias de 1991 a 2000 para Rio Grande, RS. Rio Grande, Ed. FURG, 2001.

MOLION, L. C. B. Climatologia Dinâmica da região Amazônica: mecanismos de precipitação. Revista Brasileira de Meteorologia, 22(1): 107 117, 1987;

SOUSA, E. P. P. de. Relações entre as anomalias de tsm do atlântico e pacífico e as precipitações na amazônia oriental. 2004. 80 f. Dissertação (Mestrado), Instituto de Pesquisas Espaciais, São José dos Campos, SP.

HACHBART, E. Bye Bye El Niño !!! E agora ? O que vem pela frente no clima da Terra ?. Disponível em <http://www.metsul.com/secoes/ visualiza.php?cod subsecao $=31 \&$ cod texto $=536>2007.4$ Acesso em 23/05/2008. 